Мануков М.М.

\title{
ПРЕДМЕТ ПРОКУРОРСКОГО НАДЗОРА ЗА ИСПОЛНЕНИЕМ ЗАКОНОВ СУБЪЕКТАМИ ОПЕРАТИВНО-РОЗЫСКНОЙ ДЕЯТЕЛЬНОСТИ
}

\begin{abstract}
Аннотация: в статье рассмотрены теоретические и правовые вопросы, касающиеся полномочий прокурора и содержания предмета прокурорского надзора за исполнением законов органами и должностными лицами, осуществляющими оперативно-розыскную деятельность. При этом исследованы особенности данного вида прокурорского надзора и его отличия от надзора за исполнением законов органами дознания и предварительного следствия. в статье отмечается, что согласно ст. 45 Конституции Российской Федерации в нашей стране каждому гарантируется государственная защита прав и свобод человека и гражданина. В этой связи государство обязано создать и обеспечить поддержание такого правопорядка, при котором любое физическое и юридическое лицо имело бы реальную возможность защищать свои права и законные интересы и получать со стороны государства адекватную поддержку Методологическую основу статьи составили современные достижения теории познания. В процессе исследования применялись общефилософрский, теоретический, общефилософские методы (диалектика, системный метод, анализ, синтез, аналогия, дедукция, наблюдение, моделирование), традиционно правовые методы (формально-логический), а также методы, используемые в конкретно-социологических исследованиях (статистические, экспертные оценки и др.). Указанные нормативные предписания подлежат реализации на всех направлениях функционирования прокуратуры и в полной мере относятся к такой отрасли прокурорского надзора, как надзор за исполнением законов органами, осуществляющими оперативно-розыскную деятельность (ОРД), дознание и предварительное следствие. Компетенция прокурора в этой части регламентирована положениями ст.ст. 29 и 30 Закона о прокуратуре, нормами уголовно-процессуального законодательства, а также иных федеральных законов, регулирующих деятельность судебных и иных правоохранительных органов.

Ключевые слова: надзор, прокурор, полиция, ОРД, метод, форма, представление, предостережение, контроль, полномочия.
\end{abstract}

$\mathrm{C}$ огласно ст.45 Конституции Российской Федерации в нашей стране каждому гарантируется государственная защита прав и свобод человека и гражданина. В этой связи государство обязано создать и обеспечить поддержание такого правопорядка, при котором любое физическое и юридическое лицо имело бы реальную возможность защищать свои права и законные интересы и получать со стороны государства адекватную поддержку. ${ }^{1}$

\footnotetext{
О процессуальных и оперативно-розыскных проблемах обеспечения защиты прав и законных лиц, потерпевших от преступлений см.: Фёдоров А.А., Глушков А.И. Свидетельский иммунитет как институт уголовно-процессуального права // Российский судья. 2006. № 10. С. 9-12; Глушков А.И. Взаимодействие следователя и оперативных сотрудников в рамках оперативно-розыскного обеспечения уголовного судопроизводства // Вестник Московского городского педагогического университета. Серия: Юридические науки. 2008. № 1. С. 68-73; Глушков А.И., Головко Н.В. Организация взаимодействия следователя по противодействию торговле детьми и использованию рабский труд // Административное и муниципальное прав. 2011, № 12. С. 53-56.
}

В соответствии с положениями закона «0 прокуратуре Российской Федерации» ${ }^{2}$ главной и важнейшей функцией прокурора является осуществление надзора за соблюдением Конституции РФ и исполнением законов, действующих на территории страны. Этот надзор осуществляется в целях обеспечения верховенства закона, единства и укрепления законности, защиты прав и свобод человека и гражданина, а также охраняемых законом интересов общества и государства (ч. 2 ст. 1 Закона о прокуратуре). ${ }^{3}$

\footnotetext{
2 Федеральный закон от 17 января 1992 г. №2202-I (ред. от 04.06.2014) “О прокуратуре Российской Федерации” // Ведомости Съезда народных депутатов Российской Федерации и Верховного Совета Российской Федерации от 20 февраля 1992 г. № 8. Ст. 366.

О проблемах осуществления прокурорского надзора также см.: Винокуров Ю.Е., Глушков А.И. К вопросу о структуре прокурорского надзора как вида государственной деятельности // Административное и муниципальное право. 2012. № 1. С. 30-32; Глушков А.И. Роль прокурора в обеспечении
} 
Указанные нормативные предписания подлежат реализации на всех направлениях функционирования прокуратуры и в полной мере относятся к такой отрасли прокурорского надзора, как надзор за исполнением законов органами, осуществляющими оперативно-розыскную деятельность (ОРД), дознание и предварительное следствие. Компетенция прокурора в этой части регламентирована положениями ст.ст. 29 и 30 Закона о прокуратуре, нормами уголовно-процессуального законодательства, а также иных федеральных законов, регулирующих деятельность судебных и иных правоохранительных органов.

Нетрудно заметить, что данная отрасль прокурорского надзора фактически охватывает два самостоятельных и существенно различающихся направлений правоохранительной деятельности (уголовно-процессуальное и оперативно-розыскное), которые реализуются в различных правовых сферах и регулируются автономными отраслями права.

Включение законодателем в одну надзорную отрасль указанных сфер деятельности отдельные авторы объясняют и оправдывают совпадением и общностью их целей и основных задач (выявление, предупреждение, пресечение и раскрытие преступлений, установление и изобличение лиц, их совершивших, ограждение невиновных от незаконного уголовного преследования, выявление причин и условий, способствовавших совершению преступлений, и др.). ${ }^{4}$ Однако, по нашему мнению, согласиться с обоснованностью и справедливостью подобных утверждений не представляется возможным по следующим причинам.

Как известно, оперативно-розыскная деятельность представляет собой разновидность правоохранительной деятельности, осуществляемой гласно и негласно уполномоченными законом оперативными подразделениями государственных органов в пределах их полномочий посредством проведения оперативно-розыскных мероприятий в целях защиты жизни, здоровья, прав и свобод человека и гражданина, собственности, обеспечения безопасности общества и государства от преступных посягательств. ${ }^{5}$

реализации принципа состязательности сторон на досудебных стадиях уголовного процесса // Административное и муниципальное право. 2013. № 5. С. 482-485.

4 См, напр.: Авдеев В.Н., Шелег Д.И. Прокурорский надзор: Курс лекций / под ред. В.Л. Попова. М.: ИМЦ ГУК МВД России, 2004. С.125.

5 Федеральный закон от 12.08.1995 № 144-Ф3 (ред. от 21.12.2013) “Об оперативно-розыскной деятельности" // Собрание законодательства РФ. 14.08.1995. № 33. Ст. 3349.
Следует подчеркнуть, что диапазон задач, разрешаемых в ходе ОРД, не ограничивается задачами, стоящими перед дознанием и предварительным следствием, а значительно шире. Так, например, оперативно-розыскные мероприятия могут быть произведены для установления места нахождения лиц, скрывшихся от суда или уклоняющихся от уголовного наказания, для розыска без вести пропавших, для обеспечения безопасности (государственной, военной, экономической, информационной или экологической) государства.

Указанные мероприятия допустимо осуществлять в целях обеспечения безопасности лиц, охраняемых в соответствии с законом о защите определённой категории должностных лиц и участников уголовного судопроизводства, ${ }^{6}$ а также в целях сбора сведений, необходимых для принятия решения о допуске к сведениям, составляющим государственную тайну, к работам, связанным с эксплуатацией объектов повышенной опасности.

Кроме того, само восприятие надзора за законностью осуществления ОРД в качестве структурного элемента прокурорского надзора за исполнением законов органами предварительного расследования изначально умаляет его роль и степень значимости в системе мер борьбы с преступностью и обеспечения защиты прав и законных интересов граждан.

Данное обстоятельство, на наш взгляд, также негативно влияет на работу прокуроров по обеспечению эффективности и надлежащего качества надзора за законностью оперативно-розыскной деятельности, поскольку служит препятствием признанию его в качестве одного из приоритетных направлений деятельности органов прокуратуры. Этому же в немалой степени способствует и организационная структура многих прокуратур субъектов федерации, в соответствии с которой прокуроры, осуществляющие надзор за ОРД, включены в

\footnotetext{
6 Федеральный закон от 20.04.1995 № 45-Ф3 (ред. от 03.02.2014) “О государственной защите судей, должностных лиц правоохранительных и контролирующих органов” // Собрание законодательства РФ. 24.04.1995. № 17. Ст. 1455.

См.: Прокурорский надзор в Российской Федерации: Учебник / под ред. В.И. Рохлина. СПб.: Санкт-Петербургский институт экспертов, 2000. С. 207-208; Федеральный закон «Об оперативно-розыскной деятельности»: учебное пособие. Изд. 8-е, перераб. и доп. / под ред. А.Е. Чечетина. М.: ИМЦ ГУК МВД России, 2004. С. 11-15; Прокурорский надзор: учебник / В.Н. Григорьев, А.В. Победкин, В.Н. Яшин, В.Н. Калинин. М.: Эксмо, 2006. С. 239-240.
} 
состав отраслевых отделов по надзору за следствием и дознанием. 8

Рассматривая особенности надзора за исполнением законов субъектами ОРД, следует также отметить, что данный вид надзора регламентируется не только федеральным законодательством, но и ведомственными нормативными актами, к числу которых относятся следующие:

- акты прокуратуры (специальные акты, посвященные надзору за исполнением законов в ОРД; акты, регламентирующие деятельность прокурора в отдельных отраслях или направлениях, в которых затрагиваются лишь некоторые аспекты надзора за исполнением законов в ОРД; акты, посвященные узким проблемам, к разрешению которых одновременно привлекаются прокуроры, осуществляющие надзор в различных отраслях);

- акты органов, чьи оперативные подразделения непосредственно проводят ОРД;

- совместные акты прокуратуры и органов, чьи оперативные подразделения непосредственно проводят ОРД. ${ }^{9}$

Ведущую роль здесь принадлежит приказу Генеральной прокуратуры РФ от 15 февраля 2011 г. № 33 (с изменениями на 28 января 2014 г.) «0б организации прокурорского надзора за исполнением законов при осуществлении оперативно-розыскной деятельности». ${ }^{10}$ В нём наряду с детальным изложением вопросов, подлежащих разрешению прокурорами в рамках данного направления деятельности, чётко и однозначно определены обстоятельства, определяющие содержание предмета указанного вида надзора.

В частности, в ходе организации и осуществления надзора за исполнением законов при осуществлении ОРД уполномоченные прокуроры обязаны обеспечить законные гарантии соблюдения прав человека и гражданина на неприкосновенность частной жизни, личную и семейную тайну, защиту чести и доброго имени, неприкосновенность жилища и тайну переписки, телефонных переговоров, почтовых отправлений, телеграфных и иных сооб-

\footnotetext{
8 Осипкин В.Н. Прокурорский надзор за оперативно-розыскной деятельностью: Учебное пособие. СПб.: СанктПетербургский юридический институт Генеральной прокуратуры РФ, 2001. С. 3.

9 Прокурорский надзор: учеб. пособие под ред. Ф.К. Зиннурова, В.Н. Григорьева. М.: ЮНИТИ-ДАНА; Закон и право, 2012. C. $120-121$.

10 См.: Законность. 2011, № 5.
}

щений, а также прав и законных интересов юридических лиц, установленных законом запретов при осуществлении ОРД.

Кроме того указанные должностные лица прокуратуры должны в пределах своей компетенции предпринимать меры по обеспечению законности при проведении оперативно-розыскных мероприятий, в том числе тех, на проведение которых разрешение дано судом, при принятии субъектами ОРД юридически значимых решений, при представлении результатов ОРД дознавателю, органу дознания, следователю, прокурору или в суд, а также по обеспечению соответствия законам правовых актов, издаваемых органами, осуществляющими ОРД, соблюдения порядка выполнения оперативнорозыскных мероприятий, установленного законами и правовыми актами, принятыми уполномоченными органами и предусматривающими механизм реализации законов.

Уполномоченным прокурорам при реализации своих надзорных компетенций предписано также проверять законность, обоснованность и соблюдение установленного порядка заведения дел оперативного учета и иных оперативно-служебных материалов, сроков и порядка их ведения, а также прекращения в случае решения задач ОРД или установления обстоятельств, свидетельствующих об объективной невозможности их решения.

Согласно требованиям Генерального прокурора РФ при проведении прокурорских проверок уполномоченные должностные лица должны обращать внимание на следующие обстоятельства:

- законность и обоснованность решений о производстве или прекращении оперативно-розыскных мероприятий, а также использования результатов ОРД;

- обязательность регистрации и заведения дел оперативного учёта, законность постановки и снятия с оперативного учёта лиц, в отношении которых проводятся оперативно-розыскные мероприятия;

- соответствие оперативно-розыскных мероприятий целям и задачам ОРД, а также недопустимость применения информационных систем и технических средств, наносящих ущерб жизни и здоровью людей и причиняющих вред окружающей среде;

- наличие необходимых полномочий у должностных лиц, осуществляющих оперативнорозыскные мероприятия; 
- возможность осуществления только тех оперативно-розыскных мероприятий, перечень которых определён законом об ОРД;

- наличие оснований для проведения оперативно-розыскных мероприятий, в том числе на проведение которых разрешение дано судом (срок действия вынесенного судьёй постановления не может превышать 6 месяцев, но при необходимости срок может быть продлен на основании вновь представленных материалов);

- соблюдение условий и порядка проведения оперативно-розыскных мероприятий;

- своевременность уведомления судьи органами, осуществляющими ОРД, о проведении оперативно-розыскных мероприятий, ограничивающих конституционные права и свободы граждан, без предварительного получения судебного разрешения в случаях, не терпящих отлагательства и могущих привести к совершению тяжкого преступления, а также при наличии данных о событиях и действиях, создающих угрозу государственной, военной, экономической или экологической безопасности государства;

- $\quad$ законность привлечения граждан к сотрудничеству на конфиденциальной основе и соблюдение принципа добровольного согласия с органами, осуществляющими ОРД. ${ }^{11}$
Разумеется, конечным результатом работы прокурора является принятие предусмотренных законом мер по восстановлению нарушенных при проведении оперативно-розыскных мероприятий прав и свобод человека и гражданина, возмещение причинённого вреда. Эти меры могут выражаться в устранении фактов незаконного и необоснованного ограничения прав и свобод граждан, препятствий к их использованию, выполнении действий, направленных на возмещение вреда и имущественного ущерба, при одновременном применении средств воздействия на лиц, допустивших нарушение закона.

Изложенные обстоятельства дают основания утверждать, что ключевым моментом, определяющим содержание предмета рассматриваемого вида прокурорского надзора, являются соблюдение прав и свобод человека и гражданина, установленного порядка выполнения оперативно-розыскных мероприятий, а также законность решений, принимаемых органами и должностными лицами, осуществляющими ОРД. В свете рассматриваемых проблем представляется целесообразным в структуре деятельности прокуратуры расценивать прокурорский надзор за исполнением законов органами, осуществляющими ОРД, в качестве самостоятельной отрасли надзора. ${ }^{12}$

\section{Библиография:}

1. Сухарев А.Я. Прокурорский надзор: Учебник для вузов / Под ред. А.Я. Сухарева. М.: Норма, 2005.

2. Ястребов В.Б. Учебник прокурорского надзора. 2-е изд., перераб. и доп. М.: Издательский дом «Городец», 2005.

3. Авдеев В.Н., Шелег Д.И. Прокурорский надзор: Курс лекций / под ред. В.Л. Попова. М.: ИМЦ гУК МВД России, 2004.

4. Халиулин А.Г. Предмет прокурорского надзора за процессуальной деятельностью органов дознания и органов предварительного следствия // Прокурорский надзор за процессуальной деятельностью органов дознания и органов предварительного следствия: Учебник / Под ред. проф. Смирнова А.Ф. М., 2006.

5. Прокурорский надзор в Российской Федерации: Учебник / под ред. В.И. Рохлина. СПб.: СанктПетербургский институт экспертов, 2000.

6. Федеральный закон «Об оперативно-розыскной деятельности»: учебное пособие. Изд. 8-е, перераб. и доп. / под ред. А.Е. Чечетина. М.: ИМЦ ГУК МВД России, 2004.

7. Прокурорский надзор: учебник / В.Н. Григорьев, А.В. Победкин, В.Н. Яшин, В.Н. Калинин. М.: Эксмо, 2006.

11 На данные обстоятельства указывали и другие авторы. См., напр.: См.: Осипкин В.Н. Предмет прокурорского надзора за оперативно-розыскной деятельностью. Труды Санкт-Петербургского юридического института Генеральной прокуратуры РФ. № 3. СПб, 2001. С. 34; Прокурорский надзор: учеб. пособие под ред. Ф.К. Зиннурова, В.Н. Григорьева. М.: ЮНИТИ-ДАНА; Закон и право, 2012. С. 120-121.
12 Схожую точку зрения высказывали и иные авторы. См., напр.: Чувилёв А.А., Чувилёв Ан.А. Прокурорский надзор. Вопросы и ответы М.: Новый Юрист, 1999. С. 53; Настольная книга прокурора / под ред. С.И. Герасимова. М.: НИИ проблем укрепления законности и правопорядка; изд-во «Экслит», 2002. С. 287; Авдеев В.Н., Шелег Д.И. Указ. соч. С.126; Прокурорский надзор: учебник / В.Н. Григорьев, А.В. Победкин, В.Н. Яшин, В.Н. Калинин. М.: Эксмо, 2006. С. 240-241. 
Административное и муниципальное право 8 (80) • 2014

8. Агутин А.В., Куликова Г.Л., Агеев А.Н. Организация прокурорского надзора на стадии возбуждения уголовного дела: Монография. - М., 2010.

9. Винокуров Ю.Е. и другие. Прокурорский надзор. 10-е изд., перераб. и доп. - М.: Изд-во Юрайт, 2010.

10. Прокурорский надзор: учеб. пособие под ред. Ф.К. Зиннурова, В.Н. Григорьева. - М.: ЮНИТИ-ДАНА; Закон и право, 2012.

11. Винокуров А.Ю. Прокурорский надзор за исполнением законов полицией: предмет и пределы осуществления // NB: Российское полицейское право. - 2013. - 3. - C. 24-44. DOI: 10.7256/23064218.2013.3.8913. URL: http://www.e-notabene.ru/pm/article_8913.html

12. Купреев С.С. Содержание, формы и методы административной деятельности полиции // Полицейская деятельность. - 2014. - 2. — C. 191-202. DOI: 10.7256/2222-1964.2014.2.11765.

\section{References:}

1. Sukharev A.Ya. Prokurorskii nadzor: Uchebnik dlya vuzov / Pod red. A.Ya. Sukhareva. M.: Norma, 2005.

2. Yastrebov V.B. Uchebnik prokurorskogo nadzora. 2-e izd., pererab. i dop. M.: Izdatel'skii dom «Gorodets», 2005.

3. Avdeev V.N., Sheleg D.I. Prokurorskii nadzor: Kurs lektsii / pod red. V.L. Popova. M.: IMTs GUK MVD Rossii, 2004.

4. Khaliulin A.G. Predmet prokurorskogo nadzora za protsessual'noi deyatel'nost'yu organov doznaniya i organov predvaritel'nogo sledstviya // Prokurorskii nadzor za protsessual'noi deyatel'nost'yu organov doznaniya i organov predvaritel'nogo sledstviya: Uchebnik / Pod red. prof. Smirnova A.F. M., 2006.

5. Prokurorskii nadzor v Rossiiskoi Federatsii: Uchebnik / pod red. V.I. Rokhlina. SPb.: Sankt-Peterburgskii institut ekspertov, 2000.

6. Federal'nyi zakon «Ob operativno-rozysknoi deyatel'nosti»: uchebnoe posobie. Izd. 8-e, pererab. i dop. / pod red. A.E. Chechetina. M.: IMTs GUK MVD Rossii, 2004.

7. Prokurorskii nadzor: uchebnik / V.N. Grigor'ev, A.V. Pobedkin, V.N. Yashin, V.N. Kalinin. M.: Eksmo, 2006.

8. Agutin A.V., Kulikova G.L., Ageev A.N. Organizatsiya prokurorskogo nadzora na stadii vozbuzhdeniya ugolovnogo dela: Monografiya. - M., 2010.

9. Vinokurov Yu.E. i drugie. Prokurorskii nadzor. 10-e izd., pererab. i dop. - M.: Izd-vo Yurait, 2010.

10. Prokurorskii nadzor: ucheb. posobie pod red. F.K. Zinnurova, V.N. Grigor'eva. - M.: YuNITI-DANA; Zakon i pravo, 2012.

11. Vinokurov A.Yu. Prokurorskii nadzor za ispolneniem zakonov politsiei: predmet i predely osushchestvleniya // NB: Rossiiskoe politseiskoe pravo. - 2013. - 3. - S. 24-44. DOI: 10.7256/2306-4218.2013.3.8913. URL: http://www.e-notabene.ru/pm/article_8913.html

12. KupreevS.S.Soderzhanie,formyimetodyadministrativnoideyatel'nostipolitsii//Politseiskayadeyatel'nost'._ 2014. - 2. - S. 191-202. DOI: 10.7256/2222-1964.2014.2.11765. 